\title{
Noonan syndrome
}

INSERM

\section{Source}

INSERM. (1999). Orphanet: an online rare disease and orphan drug data base. Noonan

syndrome. ORPHA:648

Noonan Syndrome (NS) is characterised by short stature, typical facial dysmorphism and congenital heart defects. 